\title{
Comparision and Analysis of Total Harmonic Distortion for IGBT and MOSFET based VS Inverter
}

\author{
Sourabh Mehto ${ }^{1}$, Rakesh Singh Lodhi ${ }^{2}$ \\ ${ }^{I}$ Department of Electrical \& Electronics, VITS Indore (M.P.)India \\ ${ }^{2}$ Department of Electrical \& Electronics, VITS Indore (M.P.)India
}

\begin{abstract}
In this paper comparision between IGBT and MOSFET based inverter is done. Total harmonic distortion is compared with the varition of fundamental frequency of output voltage of inverter. Voltage source inverter is implemented in MATLAB/Simulink software. IGBT is basically used for high power applications. Total harmonic distortion of IGBT is batter then MOSFET based voltage source inverter to control high power rating machines. Analysis of THD in resistive load is taken in MATLAB/Simulink.Fundamental frequency is varied from indian frequency to $140 \mathrm{~Hz}$.
\end{abstract}

Keywords: Matlab/Simulink, Igbt, Mosfet, Thd.

\section{Introduction}

An inverter is a device which convert dc power into ac power. Inverter can be classified into two categories such as VSI and CSI[1,2]. The IGBT and MOSFET Switch are used for making three phase inverter.IGBT combines the advantages of MOSFET and BJT,including fast switching by gate signal[6].IGBT and MOSFET can be used effectively for low and high power applications respectively. Three phase inverter output voltage, power quality has a great role on the equipment to which it is connected. THD is one of the important factors of power quality.

\section{Three Phase Volatage Source Inverter}

VSI are used for KW to MW power application. The main purpose of this method is to provide a 3- $\phi$ voltage source where it is easy to adjust the amplitude, phase and the output voltage frequencies. It consists of six IGBT/MOSFET switches $\left(S_{1}, S_{2}, S_{3}, S_{4}, S_{5}\right.$, and $\left.S_{6}\right)$. The conduction mode of VSI is 120 and 180 degree. The main advantages of VSI is that the output voltage of VSI can be varied by varying the dc link voltage and the output voltage waveform frequency rely on rating of the switches of semiconductor devices. [3]

Voltage source inverter is generally used for speed control applying by varying the frequency [5] and voltage of the voltage source. The main application of Voltage source Inverter can be seen in adjusting the speed of Induction Motor or Synchronous motor, In Uninterruptible power supply which is also known as UPS ,Frequency changer circuit.

\section{Matlab/ Simulink Of Voltage Source Inverter}

Fig 3.1 Simulink model of IGBT based VSI model is design in MATLAB software. In this model IGBT are ON in pair and for 180 degree conduction. IGBT inverter is modeled in MATLAB. For modeling the simulink model Sim power sys toolbox is used. IGBT is used in inverter as switches. By using FFT analysis overall THD of the output voltage is calculated. Here, varying the fundamental frequency the value of THD also varied and modulation index is observed here.

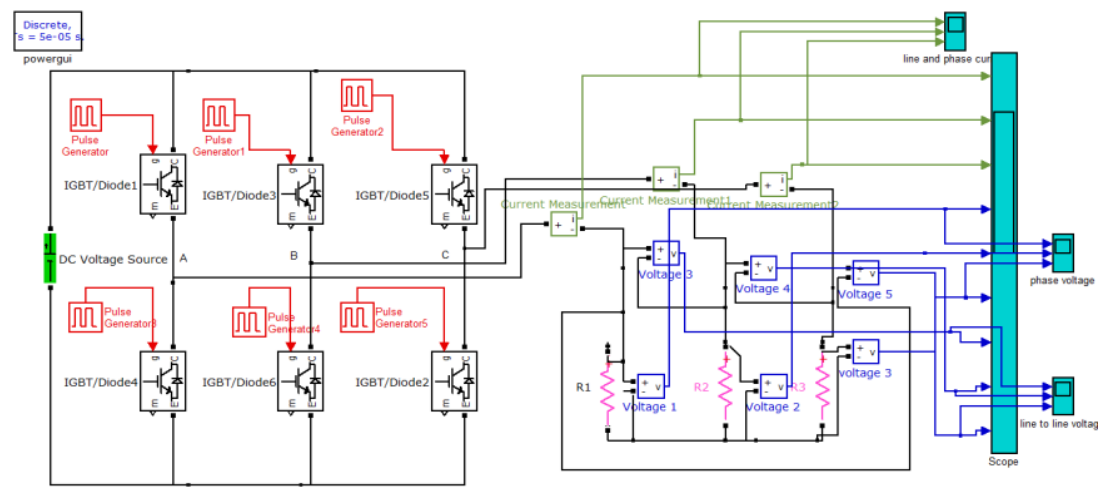

Fig. 3.1 Simulink model of IGBT based three phase inverter in MATLAB 
Simulink model of Three phase Inverter with MOSFET

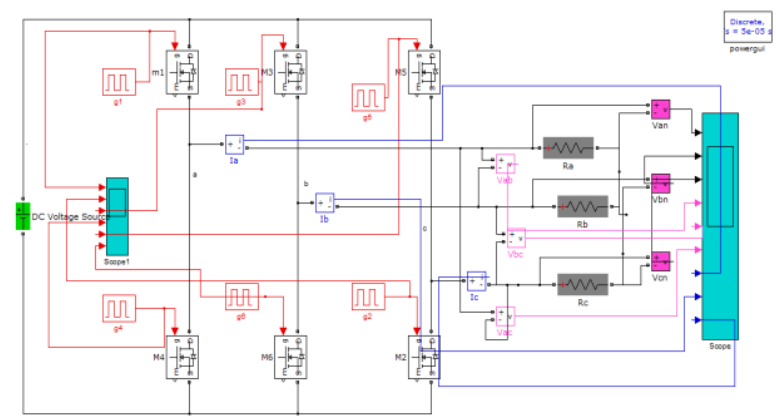

Fig 3.2 Simulink model of MOSFET based three phase inverter in MATLAB

Inverter is design with the use of MOSFET switches. Deigning and the simulation work are performed in MATLAB/ Simulink. The design model of MOSFET is same as IGBT based inverter. The design proposed here are same as IGBT to have a comparison between IGBT and MOSFET based inverter. The output voltage and the THD calculation for variable frequency is observed in fig 3.2.

\section{Figures And Tables}

Simulation Result of IGBT based three phase inverter

The performance of Inverter is observe and by varying the fundamental frequency the change in THD is calculated and the result is observed in fig.4.1
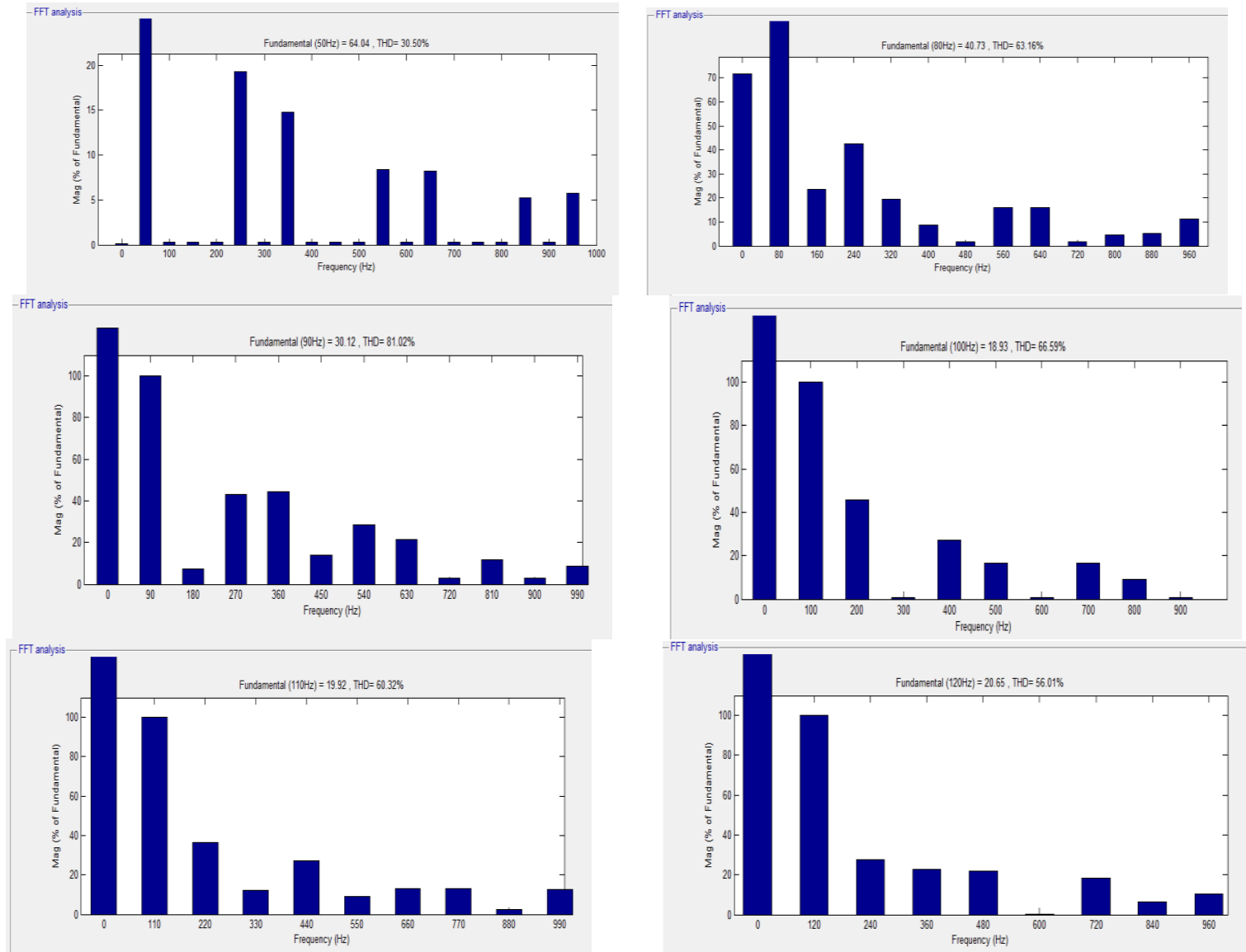

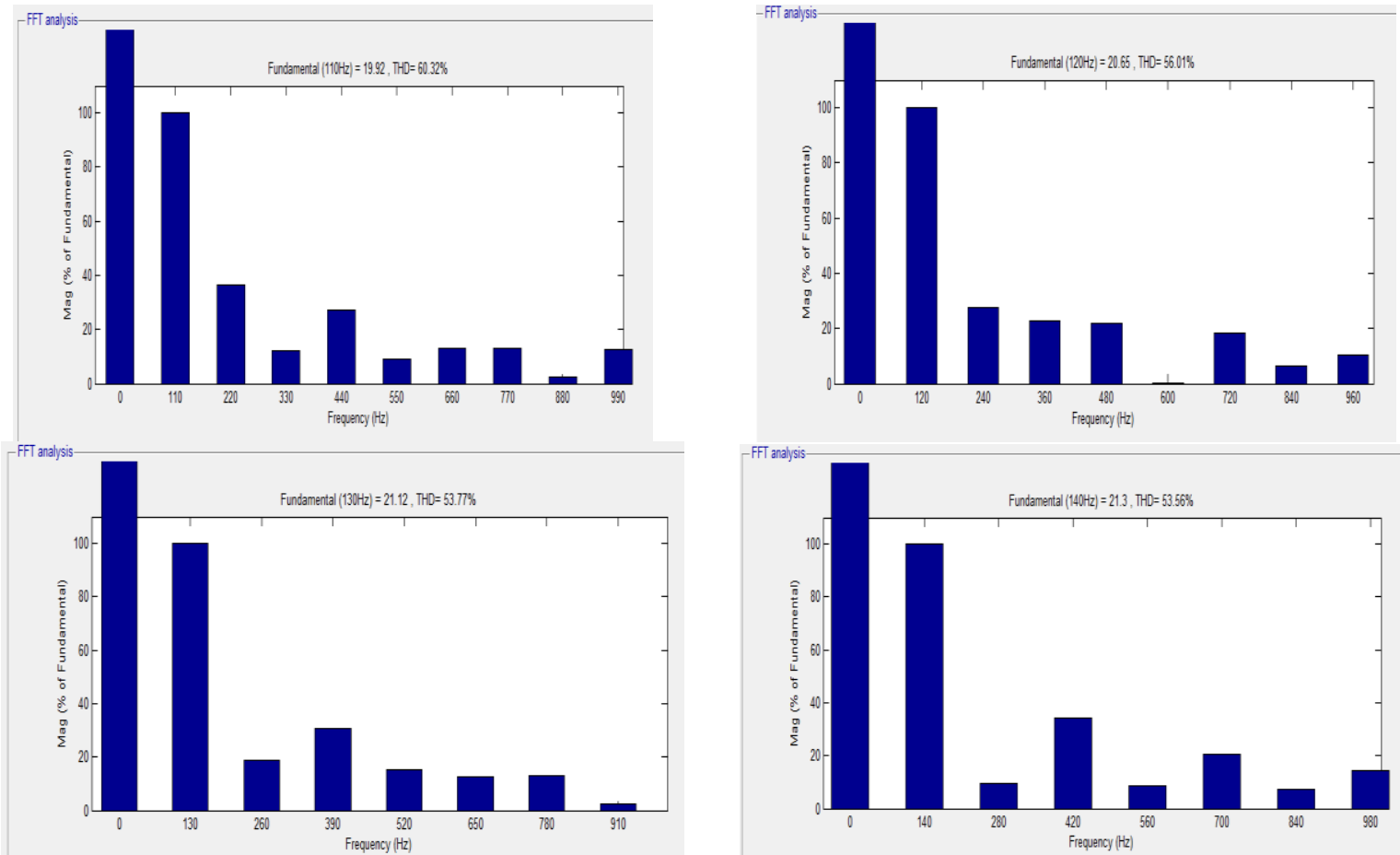

Fig 4.1 : THD results by varying fundamental frequency

\section{Simulation Result of MOSFET based three phase inverter}

The performance of Inverter is observe and by varying the fundamental frequency the change in THD is calculated and the result is observed in fig. 4.2
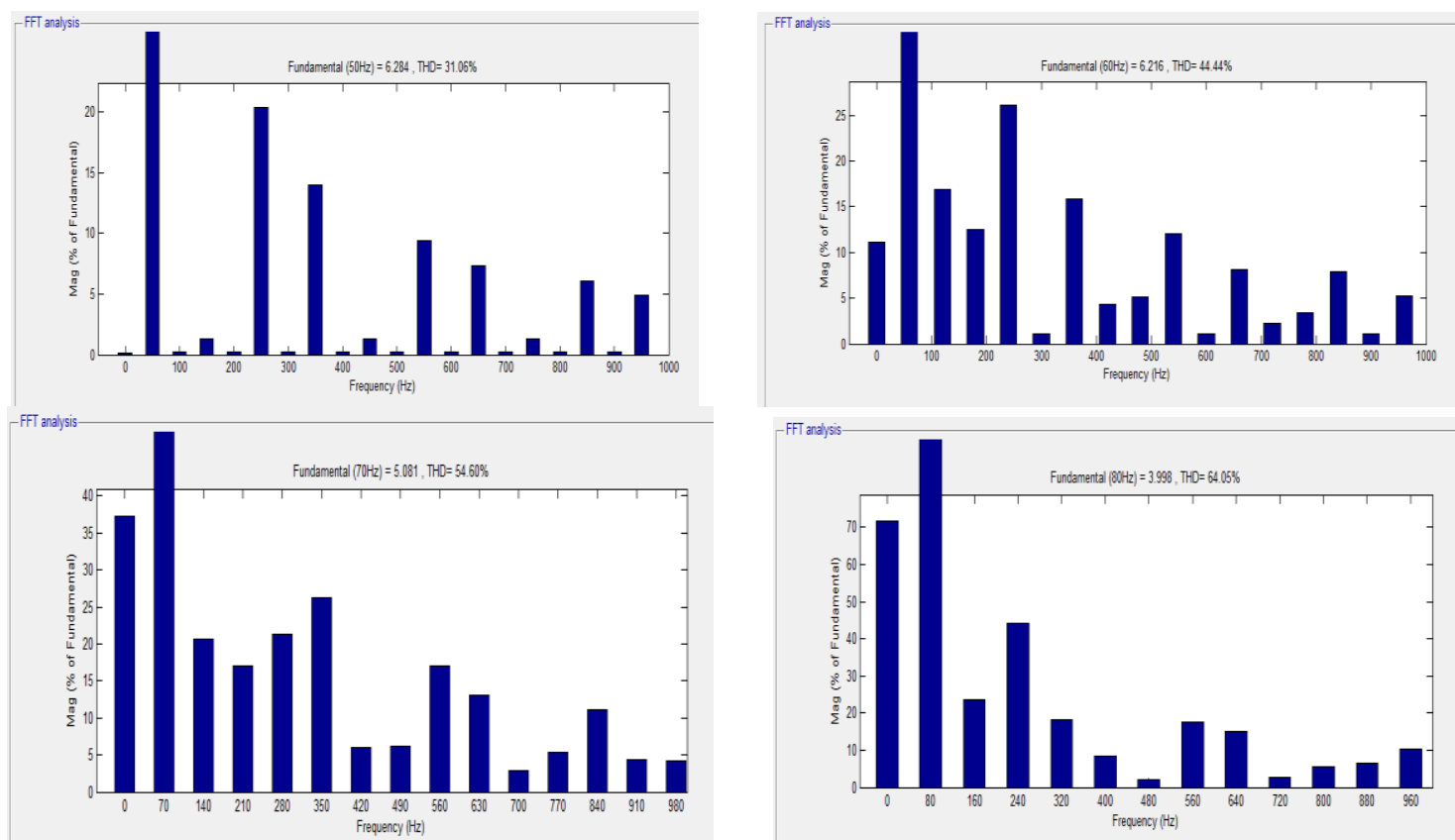

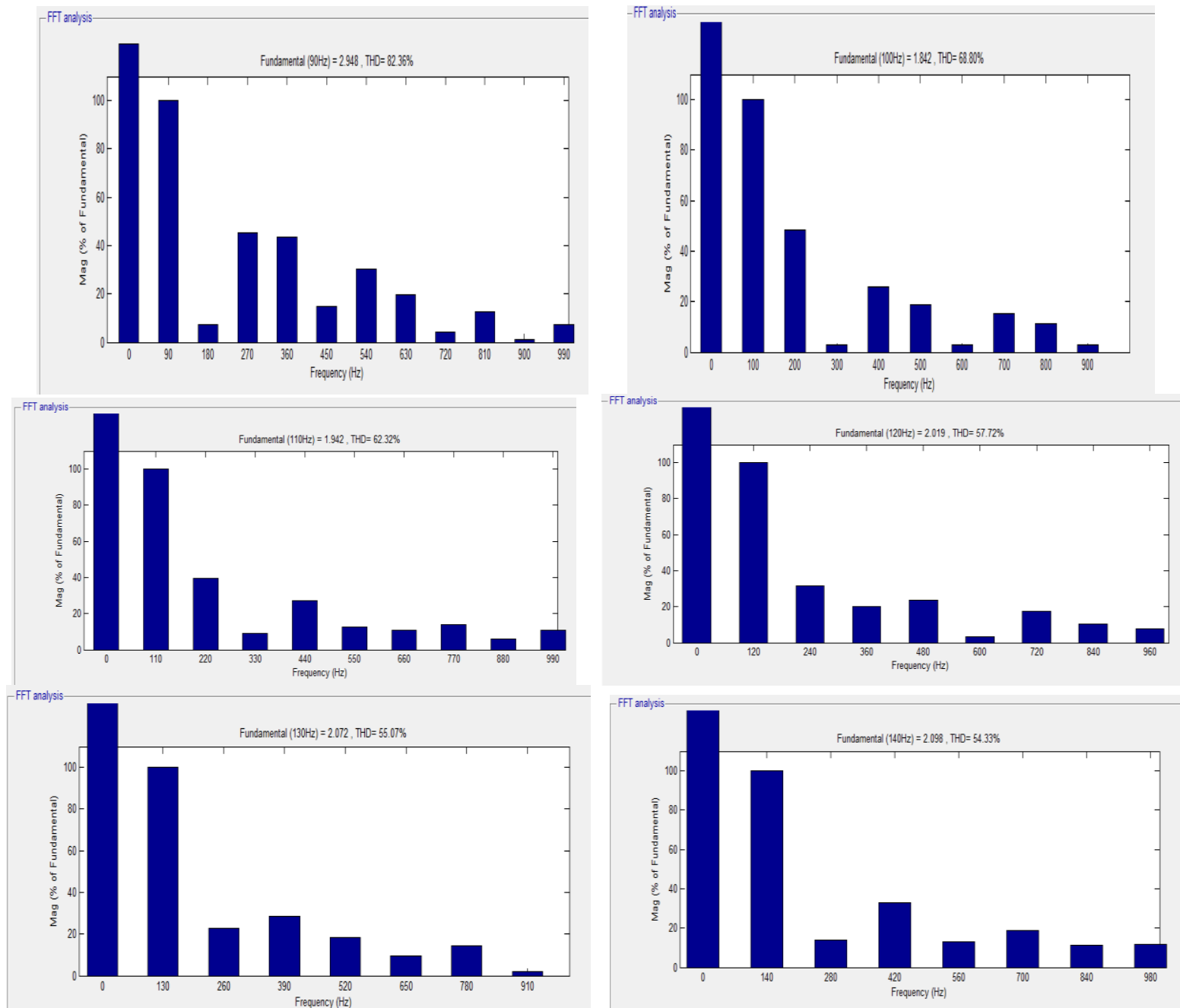

Fig 5.1 : THD results by varying fundamental frequenc.

\section{Comparision Table}

Table1: Comparison of THD in MOSFET based and IGBT based Three Phase inverter for random frequencies

\begin{tabular}{|c|c|c|}
\hline $\begin{array}{c}\text { Fundamental } \\
\text { Frequency }\end{array}$ & $\begin{array}{c}\text { IGBT based } \\
\text { inverter } \\
\text { THD percentage of output voltage }\end{array}$ & $\begin{array}{c}\text { MOSFET based } \\
\text { inverter }\end{array}$ \\
\hline & & 31.06 \\
\hline $50 \mathrm{~Hz}$ & 30.5 & 44.44 \\
\hline 60 & 43.74 & 54.6 \\
\hline 70 & 54.74 & 64.05 \\
\hline 80 & 63.16 & 82.36 \\
\hline 90 & 81.02 & 68.8 \\
\hline 100 & 66.59 & 62.32 \\
\hline 110 & 60.32 & 57.72 \\
\hline 120 & 56.01 & 55.07 \\
\hline 130 & 53.77 & 54.33 \\
\hline 140 & 53.56 & \\
\hline
\end{tabular}

\section{Conclusion}

IGBT and MOSFET based three phase inverter is simulink in MATLAB and THD of Inverter for output voltage is analyzed. Total Harmonic Distortion is increased with increasing of fundamental frequency. THD percentage of IGBT based VSI is less then MOSFET based VSI. For betterment of any system \% THD value should be minimum so we are considering IGBT switches is the best switch for three phase VSI as 
compare to MOSFET.The Switching loss of MOSFET is lower than the switching loss of IGBT , when the majority carrier device of superior switching characteristic is used. IGBT and MOSFET has a benefit of higher current density but when instantaneous large current is supply to MOSFET ,it is difficult to protect it becouse of its limitation of $\mathrm{dv} / \mathrm{dt}$ and critical current.

\section{References}

[1] Mohan undeland, Riobbins "Power Electronics converters, Application and design" john wiley and sons 2012.

[2] Cyril W. Lander "Power Electronics" Mc Graw Hill 1993.

[3] V.R.Moorthi "Power Electronic devices circuits and Industrial application" Oxford University 2010.

[4] M.S. Jamil Asgar "Power Electronics" Phi Learning 2009.

[5] Joseph Vithayathil "Power Electronics principle and application" TATA Mc Graw Hill 2010.

[6] M. H. Rashid, "Power electronics circuits, devices and applications" Prentice-Hall, Inc., july2000.

[7] G. K. Dubey, "Power semiconductor controlled drives" Prentice Hall, New Jersey, 1989.

[8] Shailendra Jain, "Modeling \& Simulation Using Matlab-Simulink” Wiley India, 2012.

[9] Biswamoy pal, Aniruddha Mukherjee "Comparative performance Analysis and THD Calculation of Carrier Signal Based IGBT and MOSFET Single Phase Inverter” IOSR Journal of Electrical and Electronics Engineering (IOSR-JEE) e-ISSN: 2278-1676, p-ISSN: 2320-3331, Volume 9, Issue 2 Ver.I Mar-Apr.2014,

[10] Debaprasad Kastha,Asim Kumar Majumdar “An Improved Starting For Voltage-Source Inverter Fed Three Phase Induction Motor Drives Under Inverter Fault Conditions”IEEE Transactions on power Electronics.Vol.15,No.4,July2000.

[11] Zheng chen,Yiying Yao,Dushan Boroyevice,Khaid T.Ngo,Kanshik Rajashekara “A 1200- V,60-A,Sic Mosfet Multichip Phase-Leg Module For High-Temperature,High Freguency,Application”IEEE Vol.29,No.5,May 2014.

[12] S. Castagno,R D Curry, and E. Loree, "Analysis and comparison of a fast turn on series IGBT stack and high voltage rated commercial IGBTS” IEEE Trans. Plasma Science,vol. 34 pp.1692-1696, October 2006.

\section{Authors Biography:}

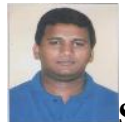

Sourabh Mehto is purshuing his M.Tech in Power Electronics form Vindhya Institute of Technology and science Indore, MP (INDIA). He completed his B.E in 2011. His field of interest for research is power Electronic, Electric Machine, Electric Drives and MATLAB.MN

Rakesh Singh Lodhi working as an Assistant Professor in Department of Electrical \& Electronics Engineering at Vindhya Institute of Technology \& Science, Indore (M.P.) India. His interested research area are power Electronics, solid state devices converters 